\title{
A RELAÇÃO INTERDISCIPLINAR ENTRE A CIÊNCIA DA INFORMAÇÃO E A CIÊNCIA DA COMUNICAÇÃO: O ESTUDO DA INFORMAÇÃO E DO CONHECIMENTO NA BIBLIOTECONOMIA E NO JORNALISMO
}

\section{Sandryne Bernardino Barreto Januário}

\section{Resumo:}

Trata da relação interdisciplinar entre a Ciência da Informação e a Ciência da Comunicação, através do estudo dos "objetos" informação e conhecimento em duas de suas áreas, a Biblioteconomia e o Jornalismo, respectivamente. Analisa ainda aspectos semelhantes e diferentes dos objetos nas áreas das Ciências.

Palavras-chave:

Ciência da informação; Ciência da comunicação; Biblioteconomia; Jornalismo; Informação; Conhecimento

\section{THE INTERDISCIPLINARY RELATIONSHIP BETWEEN INFORMATION SCIENCE AND COMMUNICATION SCIENCE: THE STUDY OF INFORMATION AND KNOWLEDGE IN LIBRARIANSHIP AND JOURNALISM}

\section{Abstract:}

This work refers to the interdisciplinary relationship between Information science and Communication science through the study of the "objects" information and knowledge, on two of its areas, Librarianship and Journalism respectively. It also examines similarities and differences of these objects in the Sciences area.

\section{Keywords:}

Information science; Communication science; Librarianship; Journalism; Information; Knowledge 


\section{INTRODUÇÃO}

“A ciência pode ser pensada como a prática de se conhecer algo ou a teoria sobre um particular objeto e não apenas um conjunto padronizado de estratégias de investigação” (BARATA, 1998, p. 21). Há ciências que são interdisciplinares, ou seja, interagirem com outras disciplinas ou áreas do saber. Entretanto, tal interação acontece em níveis diferentes. Para diferenciar esses níveis, a interdisciplinaridade foi subdividida em multidisciplinar, pluridisciplinar e transdisciplinar. Carlos (2007) cita que Hilton Japiassú (1976), um dos pioneiros do estudo da interdisciplinaridade no Brasil, conceituou esses níveis da seguinte forma:

- Multidisciplinariedade: se caracteriza por uma ação simultânea de uma gama de disciplinas em torno de uma temática comum.

Essa atuação, no entanto, ainda é muito fragmentada, na medida em que não se explora a relação entre os conhecimentos disciplinares e não há nenhum tipo de cooperação entre as disciplinas.

- $\quad$ Pluridisciplinariedade: observa-se a presença de algum tipo de interação entre os conhecimentos interdisciplinares, embora eles ainda se situem num mesmo nível hierárquico, não havendo ainda nenhum tipo de coordenação proveniente de um nível hierarquicamente superior.

- $\quad$ Transdisciplinariedade: representa um nível de integração disciplinar além da transdisciplinaridade. Trata-se de uma proposta relativamente recente no campo epistemológico. Espécie de coordenação de todas as disciplinas e interdisciplinas de um sistema.

Para Le Coadic, (1996) a interdisciplinaridade "traduz-se por uma colaboração entre diversas disciplinas que leva a interações, isto é, uma certa reciprocidade, de forma que haja, em suma, enriquecimento mútuo. A forma mais simples de ligação é o isomorfismo, a analogia”. Já Garcia (2002), acredita que a interdisciplinaridade é um modo de se trabalhar o conhecimento buscando uma reintegração de aspectos que ficaram isolados uns dos outros pelo tratamento disciplinar.

(c) Revista Digital de Biblioteconomia e Ciência da Informação,Campinas, v.7, n. 2, p.151-165, jan./jun. 2010- ISSN: 1678-765X. 
Diversas ciências são interdisciplinares, pois tem, dentre outros aspectos, o mesmo objeto como estudo principal. Utilizando como parâmetro para essa pesquisa os objetos informação e conhecimento, duas ciências se destacam pelas suas particularidades e semelhanças: a Ciência da Informação (CI) e a Ciência da Comunicação (Comunicação).

Nesse sentido, esse trabalho visa estudar tais objetos na relação interdisciplinar entre a Ciência da Informação e a Ciência da Comunicação. O contexto analisado se deterá à área da Biblioteconomia e do Jornalismo, respectivamente. Pretende-se abordar como a informação e conhecimento são estudados em cada área e algumas possibilidades de interação entre eles. Tal abordagem parte das afinidades identificadas entre a CI e a Comunicação e do incentivo para que ambas estreitem seus relacionamentos mutuamente, visando o progresso científico e social das áreas.

\section{A INFORMAÇÃO E CONHECIMENTO}

A palavra informação tem origem latina na expressão informare ou in formatio, que significa a ação de criar idéias ou noções, ou ainda, o processo de dar forma a algo, enformar. Porém, desde o surgimento da palavra até os dias atuais, diversos contextos foram dados ao termo, principalmente pelas mudanças sociais ocasionadas com o passar do tempo.

Na ciência da informação, dentre os diversos conceitos aceitos, destaca-se o de Le Coadic (2004, p.4) no qual afirma que “a informação é um conhecimento inscrito (registrado) em forma escrita (impressa ou digital), oral ou audiovisual, em um suporte”. Essa informação pode estar na forma de um documento, de um objeto, entre outros meios, e esses podem gerar o conhecimento, sempre levando em consideração o estado mental de cada indivíduo. Assim, o conhecimento é entendido por Aldo Barreto como “o destino da informação que é organizado em estruturas mentais por meio da qual um sujeito assimila a “coisa” informação”. (BARRETO, 2002a, p.19). Para o autor, a condição “informação” passou a priorizar a geração de conhecimento no indivíduo. Neste sentido, Barreto (2002b, p.69.) afirma que:

(c) Revista Digital de Biblioteconomia e Ciência da Informação,Campinas, v.7, n. 2, p.151-165, jan./jun. 2010- ISSN: 1678-765X. 
Conhecer é um ato de interpretação individual, uma apropriação do objeto informação pelas estruturas mentais de cada sujeito. Estruturas mentais não são pré-formatadas, no sentido de serem programadas pelos genes. As estruturas mentais são construídas pelo sujeito sensível, que percebe o meio. A geração de conhecimento é uma reconstrução das estruturas mentais dos indivíduos realizado através de suas competências cognitivas, ou seja, é uma modificação em seu estoque mental acumulado, resultante de uma interação com uma forma de informação. Esta reconstrução pode alterar o estado de conhecimento do indivíduo, ou porque aumenta seu estoque de saber acumulado, ou porque sedimenta o saber já estocado, ou porque reformula um saber anteriormente estocado. (destaque nosso)

A informação gera o conhecimento. Isso depende apenas do estado cognitivo de quem receberá tal informação. E o conhecimento registrado, ou seja, a transcrição de idéias, saberes, experiências, num determinado suporte, gera informação que, consequentemente, pode gerar novos conhecimentos e assim o ciclo segue e se renova.

Corroborando com essa afirmação, Mendonça (2005, p.287) afirma que a ciência é um instrumento cujo produto é a informação e que o resultado é o conhecimento. Para ela, a ciência produz a informação que gera o conhecimento, e esse conhecimento gera mais informação que produz ciência. Assim, o círculo se inicia e termina na ciência.

Todo indivíduo necessita de informações para tomar as mais diversas decisões, desde as mais simples - como escolher uma roupa - até as mais complexas - como decidir um fundo de investimento para aplicar suas rentabilidades, por exemplo -. Segundo Nascimento e Sommer (2005, p.426), a necessidade de informação é a carência de informação que uma pessoa deve suprir para realizar uma atividade profissional, uma pesquisa, para tomar uma decisão.

Por tudo isso, o estudo da informação (da sua geração, tratamento, armazenamento, acesso e uso) tem ganhado cada vez mais espaço em discussões nos meios acadêmicos e empresariais. Ela é um elemento indispensável para a cidadania e um direito de todos. É através do acesso à informação que uma pessoa pode conquistar sua independência e ter a liberdade de atuar de uma forma social mais consciente. 
Da mesma forma, Freires (2007, p.17) afirma que partindo de uma perspectiva cultural, a informação cumpre o papel de materializar valores, princípios, normas, condutas e características de um determinado grupo e/ou indivíduo. $\mathrm{O}$ autor acredita ainda que "cabe à informação a função de comunicar tais expressões da cultura, ao mesmo tempo possibilitando e promovendo as relações sociais entre estes grupos e indivíduos”.

É através dessa perspectiva, de comunicar a informação ou da informação com função de comunicar, que em determinados contextos, os conceitos - informação e comunicação podem ser confundidos. Nesse sentido, Tonini e Barbosa (2007) consideram oportuno analisar a comunicação como um "processo intermediário que permite a troca de informações entre as pessoas.” Para as autoras, a importância da comunicação da informação, de modo verbal ou escrito, é compreendida a partir do progresso tecnológico e social, resultado do poder criativo da linguagem e do raciocínio lógico das pessoas.

Assim, o estudo da informação (e da sua comunicação) com objetivo de gerar conhecimento - ou não -, é a matéria prima essencial de duas ciências em especial, a Ciência da Informação e a Ciência da Comunicação. A primeira numa abrangência mais profunda, intensa, cuja preocupação está relacionada aos significados, aos conceitos, ao acesso, uso e recuperação da informação para determinados perfis de usuários. A outra, com o interesse maior na divulgação da informação para que ela chegue ao maior número de receptores possíveis. A partir disso, faz-se necessário analisar a relação entre essas duas ciências, através dos objetos de seus estudos, para entendê-las de forma mais coerente e eficaz.

\section{A RELAÇÃO ENTRE A CIÊNCIA DA INFORMAÇÃo E CIÊNCIA DA COMUNICAÇÃO}

A Ciência da Informação é uma ciência recente, com aproximadamente 40 anos, cuja origem está relacionada, brevemente citando, à biblioteconomia, à bibliografia e à documentação. Segundo Saracevic (1996, p.47), a CI é:

Um campo dedicado às questões científicas e à prática profissional, voltadas para os problemas de efetiva comunicação do conhecimento e de registros de conhecimentos entre seres humanos, no contexto social, institucional ou individual do uso e das necessidades de informação.

(c) Revista Digital de Biblioteconomia e Ciência da Informação,Campinas, v.7, n. 2, p.151-165, jan./jun. 2010- ISSN: 1678-765X. 
Numa visão mais recente da área, o Conselho Nacional de Desenvolvimento Científico e Tecnológico (CNPq) citado por Oliveira (2005) afirma que a CI “designa o campo mais amplo de propósitos investigativos e analíticos, interdisciplinar por natureza, e que tem por objetivo o estudo dos fenômenos ligados à produção, organização, difusão e utilização de informações em todos os campos do saber”.

Quanto ao objeto de estudo da CI, segundo Freires (2007, p.67) a primeira e principal vertente de autores da área definem que o objeto é a própria informação. Nesse contexto, “a informação como um fenômeno tão amplo que abrange todos os aspectos da vida em sociedade e pode ser abordado por diversas óticas, seja a comunicacional, a filosófica, a semiológica, a sociológica, a pragmática e outras” (OLIVEIRA, 2005). Ainda de acordo com Freires, a segunda vertente para definição do objeto de estudo da CI é a comunicação ou os meios de transmissão da informação, ou seja, “o processo de geração, transferência, uso e reuso da informação” (FERNANDES, 1995, p.26). Para Le Coadic (2004, p.25) o objeto da CI é “o estudo das propriedades gerais da informação (natureza, gênese, efeitos), e a análise de seus processos de construção, comunicação e uso”. Saracevic, teórico de produção relevante no campo da Comunicação, considera o objeto de estudo da CI “o comportamento, as propriedades e os efeitos da informação em todas as suas facetas, tanto quanto os vários processos da comunicação que afetam e são afetados pelo homem”.(ORTEGA, 2004).

Já a Ciência da Comunicação é uma ciência antiga cuja história está fundamentada nos estudos da retórica Aristotélica que surgiu em meados do século II a.C. (FREIRES, 2007, p.73). Segundo Melo (1977, p.38), essa retórica se caracterizava por uma natureza nitidamente filosófica ou psicológica e abordava o processo de transmissão de informações, sobretudo pela ótica da persuasão e da influência de um interlocutor em seu meio social. A Ciência da Comunicação pode ser definida como aquela que "procura abranger a produção, o tratamento e os efeitos de símbolos e dos sistemas de signos, através das teorias analisáveis, contendo generalizações legítimas que permitam explicar os fenômenos associados à produção, ao tratamento e aos efeitos” (BERGER e CHAFEE, 1987 citado por DEVÈZE, 1998). 
Sob outra perspectiva histórica, Pierre Lévy (2007) aponta a evolução dos estudos da comunicação a partir dos instrumentos simbólicos utilizados universalmente para a comunicação entre as pessoas. Dessa forma, segundo ele, existiram cinco estágios de comunicação simbólica: a oralidade (memória oral), a escrita (signos ideográficos), o alfabeto (universalização e digitalização da escrita), os meios de comunicação de massa (informação e democracia) e o ciberespaço (capacidade de ação autônoma).

Quanto ao objeto de estudo da comunicação, José Marques de Melo afirma que o “processo de comunicação tem como objeto central a informação, transmitida por um comunicador a um receptor, utilizando um canal e um sistema de códigos específicos e posteriormente recuperados para a transmissão de novas informações” (MELO 1977, p.32). Para Muniz Sodré citado por Freires (2007, p.132), o objeto de estudo da Comunicação pode ser observado a partir de duas perspectivas distintas. Numa análise tradicional, que também pode ser denominada ontológica ou informacional, a área estuda o processo de transmissão de mensagens de um ponto a outro. Já sob um ponto de vista mais moderno, Sodré afirma que o foco de análise da Comunicação é a mediatização, ou seja, o funcionamento articulado entre as instituições de mediação da sociedade cada vez mais organizada e profissionalizada.

A relação observada entre a CI a Comunicação parte, essencialmente, do objeto “informação”, em diferentes contextos e aspectos, mas ela é o eixo central que une essas ciências. Para Bazi (2007) foi possível observar que o conceito do termo informação, associado à Ciência da Informação, “carrega consigo a fundamental importância de entender a informação como uma inscrição sociocultural de caráter conteudista, admitindo todos os processos envolvidos para se firmar como tal”. Porém, “o vocábulo na Comunicação é considerado notícia ou mensagem”. O autor afirma ainda que nessa ciência, a informação é freqüentemente reescrita, condensada e traduzida para ser publicada (disseminada) à grande massa como uma notícia. Essa, do ponto de vista estrutural, pode ser considerada como o "relato de uma série de fatos a partir do fato mais importante ou interessante; e de cada fato, a partir do aspecto mais importante ou interessante” (LAGE, 1998, p. 16 citado por BAZI, 2007).

(c) Revista Digital de Biblioteconomia e Ciência da Informação,Campinas, v.7, n. 2, p.151-165, jan./jun. 2010- ISSN: 1678-765X. 
A interdisciplinaridade também é um ponto comum entre a CI e a Comunicação. Nesse sentido, Paiva afirma que as Ciências da Informação e da Comunicação têm recorrido a um ponto de vista interdisciplinar, ou seja, predispõem-se ao diálogo com outros domínios do conhecimento - antropologia, sociologia, pedagogia, história -, e isto influi efetivamente na construção das suas metodologias, na definição dos seus fundamentos científicos e das suas bases epistemológicas, além de servir de apoio para os seus trabalhos no campo híbrido da informação e da comunicação. Ainda segundo o autor, o campo transdisciplinar formado pela CI e pela Comunicação é o "resultado de uma conjunção entre os vários procedimentos metodológicos e diferentes enfoques epistemológicos, voltados para o conhecimento dos processos midiáticos e das práticas informacionais e comunicacionais”.

Para ele, é compreensível que o feixe de reflexões teóricas sobre a informação e a comunicação dificilmente se deixe apreender nos limites de um campo homogêneo, pois a CI e Comunicação se definem antes como um domínio do conhecimento que abrange diferentes enfoques.

A efetiva relação entre a CI e Comunicação mostra-se a partir de várias dimensões, citando-se acima apenas duas delas. De um modo geral, para a CI a informação é um fenômeno, enquanto que para Comunicação é um processo. Porém, um fenômeno precisa de um processo para se efetivar, enquanto que um processo precisa de uma origem nesse caso o fenômeno informação - para ter o quê processar. Ambas estão interessadas na comunicação humana e este é um dos motivos pelos quais elas devem ser estudadas em conjunto, pois visam o mesmo fim - em aspectos diversos e/ou correlatos - mas com objetivos comuns. Partindo dessa visão, foram selecionadas duas áreas do conhecimento, a biblioteconomia e o jornalismo, que fazem parte da CI e da Comunicação, respectivamente, para que possamos estudar com mais detalhes como os objetos informação e o conhecimento se apresentam nelas. 


\section{A BIBLIOTECONOMIA E O JORNALISMO NA PERSPECTIVA DA INFORMAÇÃO E DO CONHECIMENTO.}

A história da Biblioteconomia remonta há três mil anos através do relato da primeira biblioteca primitiva, a Biblioteca de Ebla na Síria. Nela foi comprovada a existência das primeiras coleções organizadas de documentos e essa descoberta, feita em 1974, altera a própria história conhecida sobre a Síria e o Oriente Médio na época. A coleção era formada por 15000 tábuas de argila dispostas em estantes de acordo com o tema. Nessas tábuas, havia textos administrativos, literários e científicos. A escrita era a cuneiforme, não no seu idioma original sumério, mas numa língua desconhecida a qual se chamou eblaíta. Esta vem sendo considerada a origem da Biblioteconomia ao invés das famosas bibliotecas gregas. (ORTEGA, 2002, p.14)

A palavra biblioteconomia é composta por três elementos gregos - biblíon (livro) + théke (caixa, estojo, compartimento) + nomos (regra), assim a biblioteconomia é etimologicamente o conjuntos de regras de acordo com as quais os livros são organizados em espaços apropriados : estantes, salas, edifícios.

Segundo Ortega (2004), a Biblioteconomia deu origem à Bibliografia, que fundamentou a Documentação e que a partir dessa surgiram os primeiros insumos que constituiu à Ciência da Informação. Para a autora, a Biblioteconomia tem origem efetiva na atividade de preservação das unidades de conhecimento registrado, alterando-se com o tempo por meio da democratização do acesso à educação e à cultura em atividade de gestão de serviços de biblioteca [...].

A sociedade em que vivemos, denominada por muitos autores como "sociedade da informação”, vem acompanhando um aumento representativo na geração de informações. Como conseqüência dessa “explosão informacional”, surgiram grandes desafios relacionados ao gerenciamento desse volume de informação. Ela transformou-se assim, num fenômeno social contemporâneo analisado em diversos campos científicos. Segundo Barbosa et. al (2000, p.82) esse fenômeno levou a biblioteconomia a ampliar e aprofundar a observação e análise do seu objeto de estudo e pesquisa, por intermédio da assimilação de recursos de outros campos de conhecimento que lhe permitissem estudar e entender a produção e o registro de informações, seu armazenamento em diversos 
suportes, a organização para seu acesso, o processo de recuperação e as conseqüências sócio-culturais de seu uso.

Assim, o fenômeno informação, nesse contexto tido como um objeto de estudo, foi sendo gradativamente entendido como matéria prima essencial da Bibilioteconomia, e não o suporte livro como muitos pensavam, e infelizmente ainda pensam. Faz-se necessário observar que, para essa disciplina a informação tem o papel de gerar conhecimentos, por isso se estuda de forma particular a seleção, a aquisição, o tratamento, a organização e as formas de acesso e uso da informação sempre visando o público que a receberá, dada a preocupação que a mesma tem com a geração de novos conhecimentos a partir da informação acessada.

Quanto ao jornalismo, sua história está relacionada, antes de tudo, à da imprensa. A imprensa, propriamente dita, surgiu da necessidade do homem de se comunicar, seja através do processo de se informar ou de informar algo a alguém. Porém, a história da imprensa moderna só começa no século XV, com a invenção da impressão com tipos móveis por Gutenberg e o aparecimento posterior de folhas periódicas. A primeira iniciativa é do austríaco Miguel Von Aitzing, que em 1583 lança a Relatio Historica, uma publicação semestral. A partir dai, surgem jornais com periodicidade regular em Veneza, Alemanha e Holanda. (OLIVEIRA, 200_)

No Brasil, a imprensa foi introduzida com a chegada de D. João VI com o funcionamento da Imprensa Régia, de onde saiu em 10 de setembro de 1808, o primeiro jornal editado no Brasil, a Gazeta do Rio de Janeiro. O jornal, depois de passar por várias direções e denominações, sempre com caráter oficial, tornou-se, em $1^{\circ}$ de janeiro de 1892, o Diário Oficial, que se conhece até hoje. (OLIVEIRA, 200_).

A área ou disciplina da Comunicação Social, o jornalismo, tem diversas conceituações. Porém, para esse estudo, selecionamos algumas definições referentes ao contexto analisado, entre as quais a de Beltrão (1992, p.65) que define o jornalismo como “ a informação de fatos correntes, devidamente interpretados e transmitidos periodicamente à sociedade, com o objetivo de difundir conhecimentos e orientar a opinião pública, no sentido de promover o bem comum”. Na visão de Bond (1962, p.19-20), “o jornalismo tem quatro razões fundamentais de ser: informar, interpretar, orientar, entreter. Sem 
esquecer das demais, o certo é que todas as considerações apontam para a função, primeira, a da natureza da informação”.Quanto ao objeto de estudo do jornalismo, Bahia (1999, p.37) afirma que:

A informação é a principal finalidade do jornalismo. Ela deve ser verdadeira e íntegra, descobrindo e comunicando, pela imprensa, pelo cinema, pelo rádio, pela televisão ou outros meios, os fatos que pela sua própria natureza convém sejam públicos e não meramente particulares. Sua autoridade emana, principalmente, do conjunto das instituições políticas e econômicas” (destaque nosso)

Já Galarça (2007, p.4) afirma que o objeto de estudo do jornalismo é o processo de informação coletiva. Para a autora, a informação jornalística recebe o nome no meio de notícia, que pode ser definida como "uma informação relevante, de interesse público e que passou por um processo de avaliação, interpretação e publicação”.

No contexto jornalístico, a informação tem caráter público, uma vez que interessa a grupos numerosos de pessoas. Para Beltrão (1992, p.65) “as informações públicas são as de que se ocupa o jornalismo e, quando se referem a situações atuais e são divulgadas pelos veículos de comunicação coletiva denominam-se notícias”. Assim como Galarça, para Beltrão a notícia é a denominação da informação jornalística.

Como se pode observar, a informação sempre está relacionada aos históricos, conceitos, definições e objetos de estudo da Biblioteconomia e do Jornalismo. Entretanto, essa relação se difere no que se diz respeito ao "objeto" conhecimento. Para a Biblioteconomia, a essência da informação para gerar conhecimento está relacionada ao seu acesso, recuperação e uso, normalmente de uma forma específica, singular, para cada usuário. Ao Jornalismo, a informação está relacionada à divulgação, a quantidade, não necessariamente se preocupando se aquela informação noticiada vai gerar conhecimento, mas sempre visando o coletivo, o plural.

Porém, é importante salientar que ambas as áreas podem se complementar. Sabendo que o bibliotecário é um dos principais profissionais habilitados a selecionar, tratar, organizar e disseminar o acesso a informações nas mais diversas áreas e tendo em vista o excesso de informação disponível, tal situação pode acarretar em perda de tempo e retrabalho para o profissional do meio jornalístico. Nesse sentido, Nascimento e Sommer (2005, p.428) afirmam que muitas informações chegam aos jornalistas o tempo todo e eles necessitam absorvê-las rapidamente. Para isso, segundo as autoras, eles gastam muito tempo 
editando e selecionando informações pertinentes devido à sobrecarga de informação. É nesse momento que o bibliotecário através, dentre outros meios, do uso de linguagens documentárias (com vocabulários controlados) pode indexar adequadamente as informações - nos mais diversos suportes, sejam esses em CDs, VHs, livros, revistas, etc - facilitando a busca e recuperação das mesmas pelo jornalista. Essa situação pode ser observada, por exemplo, nos Cedocs (Centros de Documentação) conforme a experiência da Rede Globo de Minas Gerais, apresentada através do trabalho do Professor do curso de Comunicação e de Biblioteconomia da Universidade Federal de Minas Gerais, Delfim Afonso Jr. no VII Cinform.

\section{CONSIDERAÇÕES FINAIS}

A relação interdisciplinar entre a Ciência da Informação e a Ciência da Comunicação tem sido cada vez mais estudada dentro de suas áreas de modo a, entre outros aspectos, aproximá-las através das suas particularidades e semelhanças.

Do ponto de vista desse estudo, focamos os "objetos” informação e conhecimento na Biblioteconomia e no Jornalismo, áreas que fazem parte da CI e da Comunicação, respectivamente. O contexto analisado foi a importância da informação nesses meios e qual a preocupação dos mesmos em gerar conhecimento nos usuários / públicos nos quais eles trabalham. Foi possível observar que apesar da informação ser o objeto de estudo principal tanto da Biblioteconomia quanto do Jornalismo, as duas áreas atuam de forma diferente quando se trata do conhecimento.

A Biblioteconomia tem um foco mais particular, específico. Já o Jornalismo foca-se no global, no geral. Ambos tratam a informação para que ela possa ser organizada, editada, classificada, contextualizada, porém o fluxo da mesma se distingue quando ela chega ao seu destino final: as pessoas. Enquanto uma área trata a informação visando à formação de novos conhecimentos, a outra trata a informação visando divulgá-la, noticiá-la sem, de certa forma, preocupar-se com a geração de novos saberes.

A sociedade, de uma forma geral, precisa dessas duas áreas para ter acesso aos mais diversos tipos de informação e a partir do que já sabem, ou seja, do estado atual de

(c) Revista Digital de Biblioteconomia e Ciência da Informação,Campinas, v.7, n. 2, p.151-165, jan./jun. 2010- ISSN: 1678-765X. 
cognição de cada um, gerar novos conhecimentos e que poderão gerar novas informações e assim, sucessivamente.

Por tudo isso, acredita-se ser de vital importância o estreitamento da relação entre a Ciência da Informação e da Ciência da Comunicação visto que suas semelhanças atingem um bem comum e suas diferenças destacam suas particularidades, que são essenciais para contextos específicos da sociedade.

Sugere-se enfim, que novos estudos correlatos sejam realizados para analisar outras vertentes das duas Ciências e essa relação interdisciplinar possa ser cada vez mais concretizada. E assim, novas informações e conhecimentos possam ser gerados contribuindo com o desenvolvimento da sociedade em que vivemos.

\section{REFERÊNCIAS}

BAHIA, Juarez. Jornalismo, informação, comunicação. São Paulo: Ática, 1999.

BARATA, Rita Barradas. Epidemiologia e saber científico. Revista Brasileira de Epidemiologia. 1998, v. 1, n. 1, p. 14-27. Disponível em < www.scielo.br/pdf/rbepid/v1n1/03.pdf> Acesso em 31 out. 2008

BARBOSA, R. R. et al. Novo nome e novo paradigma: da biblioteconomia à ciência da informação. Perspect. Cienc. Inf., Belo Horizonte, v. 5, n. Especial, p. 81-91, jan./jun. 2000.

BARRETO, Aldo Albuquerque. A condição da informação. Revista São Paulo em Perspectiva, Fundação Seade-São Paulo, v. 16, n. 3, p. 67-74, 2002a.

. O tempo e o espaço da Ciência da Informação.

Transinformação, Campinas, São Paulo, v. 14, n. 1, p. 17-24, 2002 b.

BAZI, Rogério. Produção da informação nos campos da Ciência da Informação e comunicação jornalística: possíveis interfaces. Intexto, Porto Alegre: UFRGS, v. 1, n. 18, p. 1-14, janeiro/maio 2007. Disponível em < http://www.seer.ufrgs.br/index.php/intexto/article/view/6733/4035> Acesso em 14 out. 2008.

BELTRÃO, Luiz. Iniciação à filosofia do jornalismo. São Paulo: Edusp, 1992.

BOND, Fraser F. Introdução ao jornalismo: uma análise do quarto poder em todas as suas formas. 2. ed. Tradução Pinheiro de Lemos. Rio de Janeiro: Agir, 1962.

CARLOS, Jairo Gonçalves. Interdisciplinaridade no ensino médio: desafios e potencialidades. 2007. 172 f. Dissertação (Mestrado Profissionalizante em ensino de 
Ciências)-Universidade de Brasília, Brasília, 2007. Disponível em <

www.unb.br/ppgec/dissertacoes/proposicoes/proposicao_jairocarlos.pdf $>$ Acesso em 01 nov. 2008

DEVEZE, Jean. As ciências da informação e da comunicação na França: no caminho de uma hermenêutica da troca humana e social. In. . Comunicação e informação: identidades e fronteiras. São Paulo: Intercom; Recife: Bagaço, 2000. p.21 40.

FERNANDES, Geni Chaves. O objeto de estudo da Ciência da Informação.

INFORMARE - Caderno do Programa de Pós-graduação em Ciência da Informação, v. 1, n. 1, p. 25-30, jan./jun. 1995.

FREIRES, Thiago Gaudêncio Siebert. Relações entre a Ciência da Informação e as ciências da comunicação: um estudo dos conceitos de representação documentária, mediação e comunicação. 2007. Trabalho de Conclusão de Curso (Graduação em Biblioteconomia e Documentação) - Universidade de São Paulo. Disponível em < infocultura.info/rabci/trabalhos - 62k> Acesso em 03 nov. 2008

GALARÇA, S. L. S. Pirâmide invertida, lead clássico e interesse público: 50 anos depois, jornalismo impresso catarinense ainda segue padronização. In: CONGRESSO BRASILEIRO DE CIÊNCIAS DA COMUNICAÇÃO, 30., 2007, Santos. Anais do XXX Congresso da Intercom, 2007.

GARCIA, Lenise Aparecida Martins. Transversalidade e interdisciplinaridade. 2002 Disponível em < http://uvnt.universidadevirtual.br/ciencias/trans_e_inter_impre>.

Acesso em: 19 nov. 2008.

LEVY, Pierre. Revista FAMECOS, Porto Alegre n. 33, agosto de 2007. Disponível em $<$ http://www.pucrs.br/famecos/pos/revfamecos/33/pierre_levy.pdf $>$ Acesso em 02 nov. 2008

LE COADIC, Yves- François. A Ciência da Informação. Brasília: Briquet de Lemos, 1996.

2004.

A Ciência da Informação. Brasília: Briquet de Lemos,

MELO, José Marques de. Comunicação social: teoria e pesquisa. Petrópolis: Vozes, 1977. p. 9-79. Parte 1 - Teoria. (Meios de Comunicação Social, 1).

MENDONÇA, Ercilia Severina. A organização e a representação do conhecimento no tempo. Revista de Ciências Humanas. Florianópolis: EDUFSC, n.38, p.277-294, out. 2005. Disponível em < www.cfh.ufsc.br/ revista/edicoes_revista38.htm $>$ Acesso em 29 de out. 2008

NASCIMENTO, M. J.; SOMMER, Caroline. Jornalistas e o acesso a informação. Em questão, Porto Alegre, v. 11, n.2, p. 425-452, jul./dez. 2005. Disponível em $<$ www6.ufrgs.br/emquestao/pdf_2005_v11_n2/10_jornalista.pdf $>$ Acesso em 27 out. 2008

(C) Revista Digital de Biblioteconomia e Ciência da Informação,Campinas, v.7, n. 2, p.151-165, jan./jun. 2010- ISSN: 1678-765X. 
OLIVEIRA, Lindoval. A comunicação pela imprensa. In: Brasil on-line Rotário. 200_. Disponível em < www2.brasil-rotario.com.br/revista/materias/rev922/e922_p18.html -> Acesso em 24 out. 2008.

OLIVEIRA, Marlene de. Origens e evolução da Ciência da Informação. In:

(Coord.). Ciência da Informação e Biblioteconomia: novos conteúdos e espaços de atuação. Belo Horizonte: Editora UFMG, 2005. cap. 1. p. 9-28. (Coleção Didática).

ORTEGA, Cristina Dotta. Relações históricas entre Biblioteconomia, Documentação e Ciência da Informação. DataGramaZero - Revista de Ciência da Informação, v. 5, n. 5, out. 2004. Disponível em: <http://www.dgz.org.br/out04/F_I_art.htm>. Acesso em: 22 out. 2008

SARACEVIC, Tefko. Ciência da informação: origem, evolução e relações. Perspec. Ci. Inf., Belo Horizonte, v. 1, n. 1, p .41-62, jan./jun. 1996.

TONINI, R. S. S. ; BARBOSA, M. L. A. . A interdisciplinaridade da ciência da informação determinando a formação de seus profissionais. In: ENCONTRO NACIONAL DE CIÊNCIA DA INFORMAÇÃO,7., CINFORM- 2007, Salvador. Anais do VII CINFORM -Encontro Nacional de Ciência da Informação, 2007. Disponível em $<$ www.cinform.ufba.br/7cinform/soac/papers/adicionais/ReginaTonini2.pdf $>$ Acesso em 06 nov. 2008

\section{Sandryne Bernardino Barreto Januário}

Graduada em Biblioteconomia pela Universidade Federal de Pernambuco.

Pós-graduanda em Gestão e Tecnologia da Informação - UFPE. sandrynebarreto@gmail.com

Recebido em: 13/07/2009

Aceito para publicação em: jul/2009

(c) Revista Digital de Biblioteconomia e Ciência da Informação,Campinas, v.7, n. 2, p.151-165, jan./jun. 2010- ISSN: 1678-765X. 